\title{
An Overview on the Thermodynamic Techniques used in Food Chemistry
}

\section{Prabal Giri" ${ }^{*}$ and Churala Pal ${ }^{2}$}

${ }^{1}$ Department of Chemistry, Guskara Mahavidyalaya, Burdwan 713128, West Bengal, India

${ }^{2}$ Department of Chemistry, Basanti Devi College, Kolkata 700029, West Bengal, India

\begin{abstract}
The thermal behaviour of food strongly depends on its composition. The goals of food processing are to inactivate spoilage and pathogenic microorganisms and to maintain this status in storage. Using calorimetric techniques, many physicochemical effects can be observed in the temperature range between $-50^{\circ} \mathrm{C}$ and $300^{\circ} \mathrm{C}$. Biophysical techniques namely isothermal titration (ITC) and Differential Scanning Calorimetry (DSC) are used to characterize the structure and properties of food materials before and after processing to develop a fundamental understanding of the impact of processing and storage conditions. The data resulting from such studies can be used to predict the physical properties of foods under optimized condition.
\end{abstract}

Keywords: Isothermal calorimetry; Differential Scanning Calorimetry; Proteins; Food processing; $\beta$-glucosidase

\section{Introduction}

Diverse biophysical techniques including thermal and non-thermal methods are utilized in processing and preservation of food materials and in manufacture of value added products. The food processing aims the inactivation of spoilage and pathogenic microorganisms during storage. Alteration takes place in food components, including carbohydrates, lipids, vitamins, and most importantly, proteins during processing. Such changes lead to structural and functional changes in foods at the micro - and macromolecular levels that affect the physical, organoleptic, and nutritional properties of the food [1].

Food materials are complex biological systems containing a heterogeneous, heterophase mixture of high and low molecular weight components and their aggregates and complexes. The structure of foods may incorporate a broad range having three states of matter including dilute to concentrated liquids, solids, and mixtures of multiliquid, liquid-solid, liquid-gas, and solid-gas structures [2]. Several biophysical techniques are used to address the broad variety of structures and compositions developing a basic understanding of the impact of processing and storage conditions. The data resulting from such studies can be used to predict the physical properties of foods so that food processing and storage conditions are optimized.

Calorimetry presents itself as particularly well suited for analysis of food materials. Specifically, because many food processing methods involve thermal treatment (heating, cooling, freezing) of the materials, thermal characterization of food systems and their components leads to data that can be related directly to the processing protocols [3-5]. Determination of thermal properties of food materials, such as specific heat as a function of temperature, is essential for heat transfer and energy balance calculations [6]. Generation of a reliable database to develop equations predicting thermal properties of food materials for optimization of food processes can be accomplished by using calorimetry. Moreover, food materials and their components go through conformational and phase transitions. In the investigation of foods using thermal analysis and calorimetric techniques, many physicochemical effects can be observed in the temperature range between $-50^{\circ} \mathrm{C}$ and $300^{\circ} \mathrm{C}$ [7]. These thermal phenomena may be either endothermic or exothermic as presented in Table 1. Calorimetry data can be analyzed to evaluate the thermal and thermodynamic stability of various phases for a rational design of food product formulations and process conditions. Response to some perturbation caused from heat effects can be measured by Calorimetry. Two distinct ultrasensitive calorimetric techniques namely Isothermal Titration Calorimetry (ITC) and Differential Scanning Calorimetry (DSC) cover the application of thermodynamic techniques in food science. In DSC perturbation is a change in temperature of the sample whereas in ITC, the perturbation is the introduction of new material into the sample [8-11].

While the calorimetric technique is powerful, the validity and utility of the data depend strongly on the careful use of the equipment and correct interpretation of data. Due to the ultrasensitive instrumental set up, calorimetric data depends strongly on the conditions maintained during the experiment [12]. In choosing the calorimetry parameters, one should follow the following guidelines as provided by Haines [13]:

a. Time scale: Especially in dynamic measurement systems, for events to be detected the experimental time scale should match the time scale of the observed event.

b. Magnitude of the heat flow: If the energy associated with the transition is small, it can lead to ambiguities in its detection. Increasing the scanning rate enhances the signal; however, it may cause deviation from equilibrium conditions, which requires models beyond the standard equilibrium thermodynamics treatment of calorimetric data.

c. Moisture loss during experiment: Biological samples in general are high moisture content materials. If the sample cell is not sealed well, the moisture content of the sample will change due to evaporation during the course of experiment. This may lead to overestimation of the transition temperature as well as the transition enthalpy change.

d. Interpretation of overlapping peaks: Biological samples may contain multiple components that undergo thermally induced transitions at similar temperatures.

The advantages of using calorimetry for study of food components can be summarized as follows [14-16]:

*Corresponding author: Prabal Giri, Department of Chemistry, Guskara Mahavidyalaya, Burdwan 713128, West Bengal, India, Tel: 919-433-134-75; E-mail: prabalgiri@yahoo.co.in

Received October 28, 2014; Accepted November 20, 2014; Published November 24, 2014

Citation: Giri P, Pal C (2014) An Overview on the Thermodynamic Techniques used in Food Chemistry. Mod Chem appl 2: 142. doi:10.4172/2329-6798.1000142

Copyright: (c) 2014 Giri P, et al. This is an open-access article distributed under the terms of the Creative Commons Attribution License, which permits unrestricted use, distribution, and reproduction in any medium, provided the original author and source are credited. 


\begin{tabular}{|c|c|c|c|c|c|c|c|}
\hline Types of food & Yeast & Bacteria & Carbohydrate & Protein & Fat & Starch & Enzyme \\
\hline $\begin{array}{c}\text { outcome } \\
\text { (exothermic) }\end{array}$ & fermentation & $\begin{array}{l}\text { growth, metabolism, } \\
\text { fermentation }\end{array}$ & $\begin{array}{l}\text { crystallization, } \\
\text { decomposition }\end{array}$ & $\begin{array}{l}\text { aggregation, } \\
\text { crystallization }\end{array}$ & $\begin{array}{l}\text { crystallization, } \\
\text { oxidation }\end{array}$ & $\begin{array}{l}\text { retrogradation, } \\
\text { oxidation }\end{array}$ & $\begin{array}{l}\text { aggregration, } \\
\text { enzymatic reaction }\end{array}$ \\
\hline $\begin{array}{c}\text { outcome } \\
\text { (endothermic) }\end{array}$ & - & - & $\begin{array}{l}\text { melting, glass } \\
\text { transition }\end{array}$ & denaturation & denaturation & $\begin{array}{c}\text { gelatanization, glass } \\
\text { transtion }\end{array}$ & denaturation \\
\hline
\end{tabular}

Table 1: Exothermic and endothermic outcomes on food materials.

a) Calorimetric methodology does not impose any prerequisite on the physicochemical properties of the experimental sample unlike spectroscopic method to have in pure state or presence of chromophore.

b) Model independent and direct determination of enthalpy change $(\Delta \mathrm{H})$ and change in heat capacity at constant pressure $\left(\Delta \mathrm{C}_{\mathrm{p}}\right)$ is feasible.

c) Materials do not have to be uniform or have to be a homogeneous mixture. In fact, in addition to pure materials, the technique can be used to evaluate the interactions among the components in a complex system and how the interactions are altered by the processing.

d) Sample preparation for calorimetric analysis is very simple and can be handled without trouble by the researchers.

Today, the instruments are highly developed for accurate measurement of thermal events. The theory behind the technique is well developed, which facilitates interpretation of the data $[17,18]$. In this paper, the special emphasis has given on the working principle, methods and application of the thermodynamic techniques used namely DSC and ITC used frequently in food chemistry.

\section{Differential Scanning Calorimetry}

Differential Scanning Calorimetry, which measures heat capacity as a function of temperature, is an well-established thermal analysis technique that detects and monitors thermally induced conformational transitions and phase transitions as a function of temperature $[19,20]$. During temperature scanning, depending on the complexity of the material, many peaks or inflection points (one to several) reflecting the thermally induced transitions can be observed. The direction of the peak corresponds to the nature of the transition, being heat absorbing (endotherms) or heat releasing (exotherms). While melting of solids and denaturation of proteins display endotherms, crystallization of carbohydrates and aggregation of proteins manifest themselves as exotherms.

DSC is a thermoanalytical technique in which the difference in the amount of heat required to increase the temperature of a sample and reference are measured as a function of temperature. Both the sample and reference are maintained at nearly the same temperature throughout the experiment. Generally, the temperature program for a DSC analysis is designed such that the sample holder temperature increases linearly as a function of time. The reference sample should have a well-defined heat capacity over the range of temperatures to be scanned. The basic principle underlying this technique is that, when the sample undergoes a physical transformation such as phase transitions, more (or less) heat will need to flow to it than the reference to maintain both at the same temperature. Whether more or less heat must flow to the sample depends on whether the process is exothermic or endothermic. By observing the difference in heat flow between the sample and reference, differential scanning calorimeters are able to measure the amount of heat absorbed or released during such transitions. Thus the result of a DSC experiment is a curve of heat flux versus temperature. DSC can be used to measure a number of characteristic properties like crystallization temperature of solids, oxidative stability of samples, used in the pharmaceutical and polymer industries etc. The temperatures for the endothermic and exothermic transitions and the heat involved in such transitions are measured using a calorimeter. Inflection points are indicative of glass transitions; that is, transitions from a glassy to rubbery state. The transition temperatures $\left(\mathrm{T}_{\text {peak }} / \mathrm{T}_{\mathrm{g}} / \mathrm{T}_{\mathrm{m}}\right)$ reflect the thermal stability of the phase or state going through the transition. One can extract from calorimetry data values for the thermal and thermodynamic changes in free energy $(\Delta \mathrm{G})$, enthalpy $(\Delta \mathrm{H})$, entropy $(\Delta \mathrm{S})$, and heat capacity $\left(\Delta \mathrm{C}_{\mathrm{p}}\right)$ of the various transitions in addition to determination of the bulk heat capacity of the material [20].

In this context, it would be quiet unjustified if the older technique Differential Thermal Analysis (DTA) is not mentioned under discussion. In this technique it is the heat flow to the sample and reference that remains the same rather than the temperature. When the sample and reference are heated identically, phase changes and other thermal processes cause a difference in temperature between the sample and reference. Both DSC and DTA provide similar information. DSC measures the energy required to keep both the reference and the sample at the same temperature whereas DTA measures the difference in temperature between the sample and the reference when they are both put under the same heat. DTA is an older technique than DSC. So DSC is more sophisticated and improved than DTA. DTA instrument can be used at very high temperatures and in aggressive environments where DSC instrument may not work. In DSC, influence of sample properties on the area of the peak is comparatively lower than in DTA $[21,22]$.

The basis for thermodynamic study of food materials is that the relevant initial and final states (pre-processing and post processing states) can be defined and the energetic and structural differences between these states can be measured using calorimetric instrumentation. To this end, calorimetry can be used to evaluate the effect of other physical and chemical variables by comparing the thermo grams of the materials before and after exposure to the variable outside the calorimetry [23]. However, in most food processing food ingredients are mixed or diluted with a liquid (water, milk) or with a powder (sugar, salt, yeast). For simulation of such transformations and interactions, the limited volume and the lack of in situ mixing constitute the major drawbacks of the DSC technique.

\section{Brief instrumental procedure of DSC}

Experimental set up of a differential scanning calorimeter is represented in Figure 1(A). In a series of DSC scans, both the sample and reference cells are loaded with buffer solution, equilibrated at $10^{\circ} \mathrm{C}$ for $15 \mathrm{~min}$ and scanned from 10 to $120^{\circ} \mathrm{C}$ at a scan rate of $50^{\circ} \mathrm{C} /$ hour [20]. The buffer scans were repeated till reproducible and on cooling, the sample cell is rinsed and loaded with sample. The DSC thermograms of excess heat capacity versus temperature plots are analyzed using a variety of softwares like Origin 7.1, CALISTO, Pyris ${ }^{\mathrm{TM}}$, Proteus 7.0 etc. available in the market. The area under the experimental heat capacity $\left(\mathrm{C}_{\mathrm{p}}\right)$ curve is used to determine the calorimetric transition enthalpy $\left(\Delta \mathrm{H}_{\text {cal }}\right)$ given by the equation

$$
\Delta H_{c a l}=\int C_{p} d T
$$






Figure 1: Experimental set up of (A) Differential scanning and (B) Isothermal titration calorimeter.

Where $\mathrm{T}$ is the absolute scale temperature in Kelvin. This calorimetrically determined enthalpy is model-independent and is thus unrelated to the nature of the transition. The temperature at which excess heat capacity is at a maximum defines the transition temperature $\left(\mathrm{T}_{\mathrm{m}}\right)$. The model-dependent van't Hoff enthalpy $\left(\Delta \mathrm{H}_{v}\right)$ is obtained by shape analysis of the calorimetric data and the cooperativity factor is obtained from the ratio $\Delta \mathrm{H}_{\text {cal }} / \Delta \mathrm{H}_{\mathrm{v}}$ [24]. Comparison of the model independent calorimetrically determined $\Delta \mathrm{H}_{\text {cal }}$ value with the $\Delta \mathrm{H}_{\mathrm{v}}$ value assesses the validity of the assumptions employed in the derivation of the van't Hoff relation. Specifically, it is assumed that the transition from the ordered, low temperature form to the disordered, high temperature form passes through no thermodynamically significant intermediate states (twostate assumption); that is, there is no partial unfolding of the protein in the denaturation pathway. The $\Delta \mathrm{H}_{\mathrm{v}}$ reports the enthalpy change associated with disruption of a single cooperative unit, the fraction of the protein that acts as a single thermodynamic unit.

\section{Isothermal Titration Calorimetry}

Most biological processes involve one or more binding events. The types of binding reactions are varied and include, but are not limited to, assembly of protein subunits into functional enzyme complexes, formation of enzyme-inhibitor complexes, formation of proteinnucleic acid complexes, enzyme-substrate binding, and enzymecofactor binding. These binding processes can be described in terms of the standard thermodynamic parameters. A predictive understanding of the binding process can be achieved by measurement of the binding thermodynamic parameters. All of the binding processes enumerated above are amenable to analysis by some variation of ITC experiment [25]. Because the binding sites for small molecules to proteins tend to be well defined and small in number, and because most of the binding reactions involve a nonzero enthalpy change, protein -small molecule interactions frequently are particularly well suited to examination by isothermal titration calorimetry.

Here, we consider a simple association (without reaction) defined by the equilibrium $\mathrm{nL}+\mathrm{M} \leftrightarrow \mathrm{ML}_{\mathrm{n}}$ of a small molecule $\mathrm{L}$, with a protein or other macromolecule $\mathrm{M}$, with $\mathrm{n}$ identical, non-interacting binding sites. Other types of complex equilibria are beyond the scope of this paper. An Isothermal titration calorimetry instrument consists of two identical cells composed of a highly efficient thermal conducting material (Hasteloy) surrounded by an adiabatic jacket. Sensitive thermopile/thermocouple circuits detect temperature differences between the two cells and the cells and the jacket. Heaters located on both cells and the jacket is activated when necessary to maintain identical temperatures between all components. In an ITC experiment, the macromolecule solution is generally placed in the sample cell. The reference cell contains buffer or water minus the macromolecule. Prior to the injection of the titrant, a constant power $(<1 \mathrm{~mW})$ is applied to the reference cell. This signal directs the feedback circuit to activate the heater located on the sample cell. This represents the base line signal. The direct observable measured in an ITC experiment is the time -dependent input of power required to maintain equal temperatures in the sample and reference cell. During the injection of the titrant into the sample cell, heat is taken up or evolved depending on whether macromolecular association reaction is endothermic or exothermic. For an exothermic reaction, the temperature in the sample cell will increase and the feedback power will be deactivated to maintain equal temperatures between the two cells for endothermic reactions, the reverse will occur meaning the feedback circuit will increase power to the sample cell to maintain the temperature. The heat absorbed or evolved during a calorimetric titration is proportional to the fraction of bound ligand. For the initial injections, all or most of the added ligand is bound to the macromolecule, resulting in large exothermic or endothermic signals depending on the nature of association. As the ligand concentration increases the macromolecules becomes saturated and subsequently less heat is evolved or absorbed on further addition of titrant as presented in Figure 1. The amount of heat evolved on addition of ligand can be represented by the equation

$$
Q=V_{o} \Delta H_{b}[M]_{t} K_{a}[L] /\left(1+K_{a}[L]\right)
$$

Where $\mathrm{V}_{\mathrm{o}}$ is the volume of the cell, $\Delta \mathrm{H}_{\mathrm{b}}$ is the enthalpy of binding per mol of ligand, $[\mathrm{M}]_{t}$ is the total macromolecule concentration including bound and free fractions, $\mathrm{K}_{\mathrm{a}}$ is the binding affinity and $[\mathrm{L}]$ is the free ligand concentration [26].

\section{Brief Instrumental Procedure of ITC}

ITC experiments are performed on a Microcal VP-ITC microcalorimeter (MicroCal, Northampton, MA, USA) at $20^{\circ} \mathrm{C}$. Origin 7.0 software, supplied by the manufacturer, is used for data acquisition and manipulation, as presented in Figure 1(B). All the solutions used for ITC experiments are degassed prior to use under vacuum (140 mbar, $8 \mathrm{~min}$ ). In case of ligand-protein and complexation, degassed ligand solutions are injected from the rotating syringe (290 $\mathrm{rpm}$ ) into the isothermal sample chamber containing $1.42 \mathrm{~mL}$ of protein. Corresponding control experiments to determine the heat of dilution of ligand into buffer and food component into buffer are also performed. Each injection generated a heat burst curve (micro calories 
a

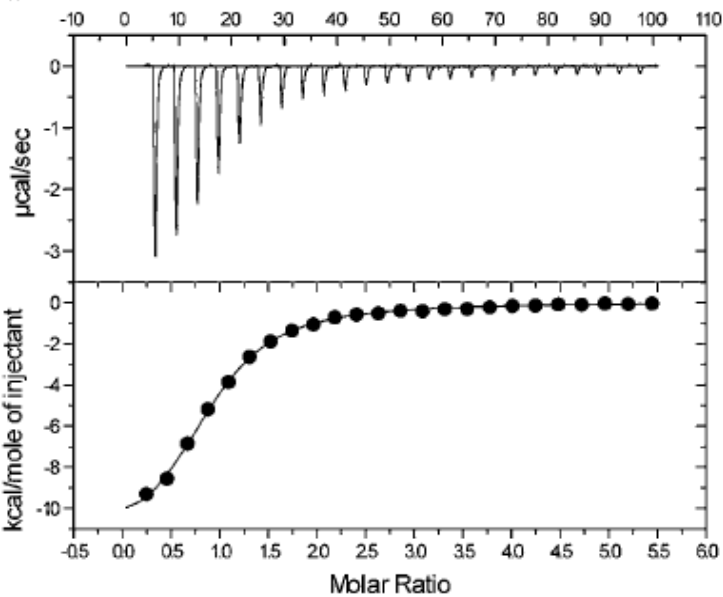

b

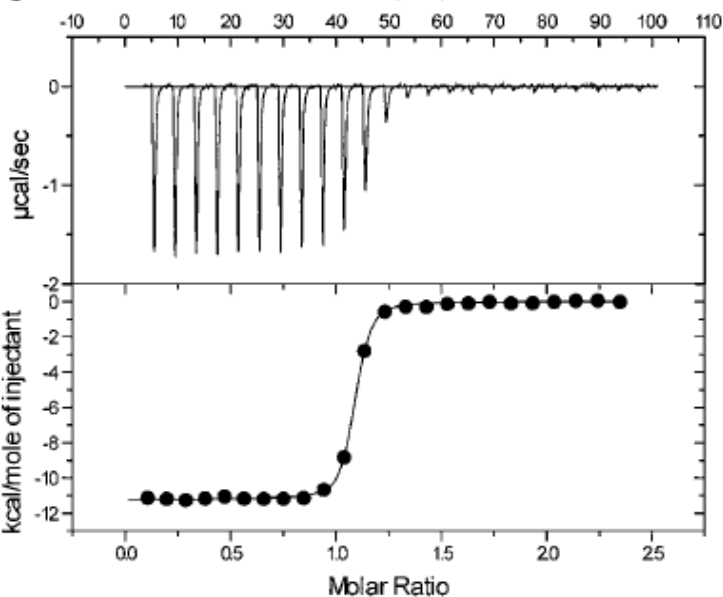

Figure 2: Isothermal titration calorimetry of binding of two inhibitors to $\beta-$ glucosidase.

(a) The raw data (upper panel) and the integrated data with fitted curve (lower panel) for an inhibitor with $K=1.25 \times 10^{5} \mathrm{M}^{-1}$. (b) An inhibitor with $K=1.5$ $\times 10^{5} \mathrm{M}^{-1}[18]$.

per second) the area under which is determined by integration (using market available software) that gives the measure of the heat of reaction associated with the injection. The heat associated with each control is subtracted from the corresponding heat associated with the ligandfood component injection to give the heat of ligand binding for that injection. The resulting data were analyzed using Origin software to estimate the binding affinity $\left(\mathrm{K}_{\mathrm{a}}\right)$, the binding stoichiometry $(\mathrm{N})$, and the enthalpy of binding $\left(\Delta \mathrm{H}_{\mathrm{o}}\right)$. The free energies $\left(\Delta \mathrm{G}_{\mathrm{o}}\right)$ are calculated using the standard relationship [11],

$$
\Delta \mathrm{G}_{\mathrm{o}}=-\mathrm{RT} \ln \mathrm{K}_{\mathrm{a}}
$$

Where $\mathrm{R}$ is $1.987 \mathrm{cal} \mathrm{mol}^{-1} \mathrm{~K}^{-1}$ and $\mathrm{T}$ is represented in Kelvin for the appropriate temperature.

The binding free energy coupled with the binding enthalpy derived from the ITC data allowed the calculation of the entropic contribution to the binding $\left(\mathrm{T} \Delta \mathrm{S}_{\mathrm{o}}\right.$ ), where $\Delta \mathrm{S}_{\mathrm{o}}$ is the calculated binding entropy using the standard relationship,

$$
T \Delta S_{o}=\Delta H_{o}-\Delta G_{o}
$$

Each experiment is repeated at least three times and the error values that reflect the standard deviations among the different runs were always less than $10 \%$, which indicates the quality of data. The ITC profile of binding of two inhibitors to $\beta$-glucosidase is shown in Figure $2[18]$.

\section{Calorimetry of Proteins}

As the food industry begins to take advantage of recent developments in protein chemistry by introducing enzymes and structural proteins into modern food materials and their processing, detailed understanding of protein chemical and physical properties becomes increasingly important. Development of a predictive understanding of the energetics-structure-function relationships will be required to fully exploit the possibilities presented to engineer proteins with novel substrate specificity or enhanced physical properties, including thermal stability, $\mathrm{pH}$, and ionic strength optima.

To fully exploit the structural and catalytic properties of proteins it is critical to develop a predictive understanding of their functions and stability as a function of temperature and solution conditions. Monitoring the unfolding of a macromolecule induced by exposure to elevated temperature is a classical method for evaluating stability. DSC is particularly well suited to characterization of protein stability. The thermodynamic characterization of the protein unfolding process derived from DSC data can be used to predict the stability of the protein at any temperature. Binding equilibria between a protein and a small molecule effector, such as a cofactor or drug, or a second protein subunit, can alter the protein's denaturation temperature. If the second molecule binds more tightly to the folded form of the protein than to the unfolded form, the denaturation will shift to higher temperature. Conversely, preferential binding to the unfolded form shifts the denaturation to lower temperature. DSC thermograms are particularly well suited to measure very tight binding based on the observed binding - induced changes in the heat capacity versus temperature profiles. The simulated DSC thermogram of a small globular protein is shown in Figure 3 [27].

Isothermal calorimetry is an extremely general technique as it measures heat production rate, which accompanies nearly all physical, chemical and biological processes. The applications of ITC in food sciences include studies on wound respiration, quantification of cell

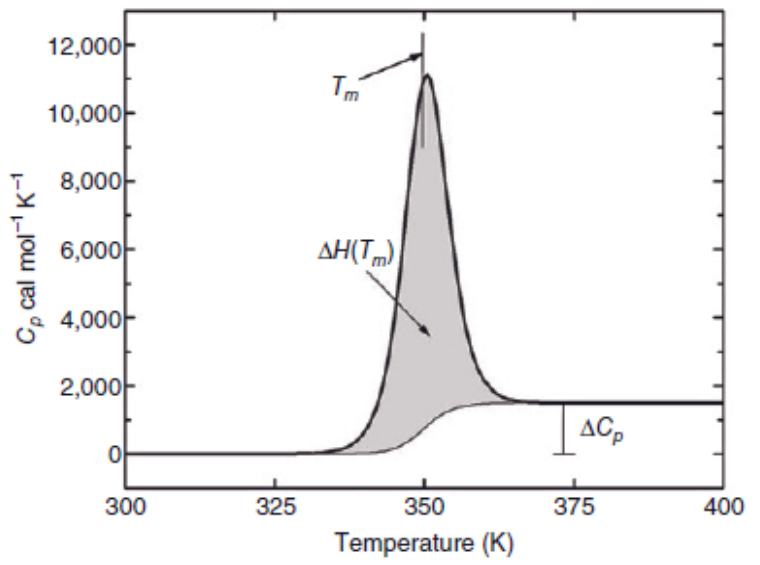

Figure 3: Simulated DSC thermogram of a small globular protein. The excess heat capacity versus temperature curve is calculated using $\mathrm{T} \mathrm{m}=350$ $\mathrm{K}, \Delta \mathrm{H}=100 \mathrm{kcal} / \mathrm{mol}$, and $\Delta \mathrm{C} \mathrm{p}=1.5 \mathrm{kcal} / \mathrm{mol}-\mathrm{K}[27]$. 
Citation: Giri P, Pal C (2014) An Overview on the Thermodynamic Techniques used in Food Chemistry. Mod Chem appl 2: 142. doi:10.4172/23296798.1000142

damage during blanching and microbiological fermentation of milk, beer and pre-biotic foods [28-30].

\section{Conclusion}

Modern ultrasensitive calorimetry provides powerful tools for understanding the stability of proteins in solution, the forces that maintain their folded structures, and their interactions with other macromolecules and small molecules. Differential Scanning Calorimetry quantifies the thermal $\left(\mathrm{T}_{\mathrm{m}}\right)$ and thermodynamic $(\Delta \mathrm{G})$ stabilities of the protein. The thermodynamic origins of the stability $\left(\Delta \mathrm{H}, \Delta \mathrm{S}\right.$, and $\left.\Delta \mathrm{C}_{\mathrm{p}}\right)$ can be interpreted to dissect the forces maintaining the folded structure and how they depend on the structure of the protein and the solution conditions. The model-independent values derived directly from the DSC thermogram can be compared to modeldependent values derived from the shape of the DSC curves to gain insight into the unfolding mechanism and aggregation. Isothermal titration calorimetry provides a means to directly measure the heat of interaction $(\Delta \mathrm{H})$ of a protein with another macromolecule or with small molecules.

Application of models for the association reaction provides detailed thermodynamic characterization $\left(\mathrm{K}_{\mathrm{a}}, \Delta \mathrm{G}, \Delta \mathrm{S}\right.$ and $\left.\Delta \mathrm{C}_{\mathrm{p}}\right)$ of the binding process. Taken together, the techniques of modern solution calorimetry provide a predictive understanding of the stability of a protein and its interactions with other molecules as a function of temperature and solution conditions.

\section{References}

1. Lewis MJ (1990) Physical properties of foods and food processing systems Woodhead Publishing Ltd., Abington Hall, Abington, Cambridge CB1 6AH, England.

2. Wilkinson C, Dijksterhuis GB, Minekus M (2000) From food structure to texture Trends Food Sci Tech 11: 442-450.

3. Biliaderis CG (1983) Differential scanning calorimetry in food research-A review. Food Chem 10: 239-265.

4. Roos YH (2003) Thermal analysis, state transitions and food quality. J Therm Anal Calorim 71: 197-203.

5. Ghai R, Falconer RJ, Collins BM (2012) Applications of isothermal titration calorimetry in pure and applied research--survey of the literature from 2010. J Mol Recognit 25: 32-52.

6. Kaletunc G (2007) Prediction of heat capacity of cereal flours: a quantitative empirical correlation. J Food Eng 82: 589-594.

7. Aguilera JM (2005) Why food microstructure? J Food Eng 67: 3-11.

8. Sturtevant JM (1987) Biochemical Applications of Differential Scanning Calorimetry. Annu Rev Phy Chem 38: 463-488.

9. Freire E (1995) Differential scanning calorimetry. Methods Mol Biol 40: 191218

10. Jelesarov I, Bosshard HR (1999) Isothermal titration calorimetry and differential scanning calorimetry as complementary tools to investigate the energetics of biomolecular recognition. J Mol Recognit 12: 3-18.

11. Lewis EA, Murphy KP (2005) Isothermal titration calorimetry. Methods Mol Bio 305: 1-16.

12. Hohne GWH, Hemminger W, Flammersheim HJ (2003) Differential Scanning Calorimetry: an Introduction for Practitioners. 2nd Edition. Springer - Verlag Berlin; New York, USA.
13. Haines PJ (1995) Thermal Methods of Analysis, Principles, Applications and Problems. Blackie Academic \& Professional, Glasgow, USA.

14. Tan CP, CheMan YB (2002) Recent developments in differential scaning calorimetry for assessing oxidative deterioration of vegetable oils. Trends Food Sci Tech 13: 312-318.

15. Gabbott $P$ (2008) Principles and applications of thermal analysis. John Wiley \& Sons Ltd., The Atrium, Southern Gate, Chichester, West Sussex, PO 19 8SQ, England.

16. Singh J, Kaur L, McCarthy OJ (2007) Factors influencing the physic-chemical, morphological, thermal and rheological properties of some chemically modified starches for food applications- a review. Food Hydrocolloid 21: 1-22.

17. Sturtevant JM (1977) Heat capacity and entropy changes in processes involving proteins. Proc Natl Acad Sci U S A 74: 2236-2240.

18. Zechel DL, Boraston AB, Gloster T, Boraston CM, Macdonald JM, et al. (2003) Iminosugar glycosidase inhibitors: structural and thermodynamic dissection of the binding of isofagomine and 1-deoxynojirimycin to beta-glucosidases. J Am Chem Soc 125: 14313-14323.

19. Ladbury JE, Doyle ML (2004) Biocalorimetry 2 Applications of calorimetry in the biological sciences. John Wiley \& Sons Ltd., The Atrium, Southern Gate, Chichester, West Sussex, PO $198 \mathrm{SQ}$, England.

20. Giri P (2009) Biophysical studies on the interaction of plant alkaloids with polyadenylic acid structures. PhD Thesis, Jadavpur University, Kolkata, India.

21. Vold MJ (1949) Differential thermal analysis. Anal Chem 21: 683-688.

22. McElhaney RN (1982) The use of differential scanning calorimetry and differential thermal analysis in studies of model and biological membranes. Chem Phys Lipids 30: 229-259.

23. Farkas J, Mohacsi-Farkas C (1996) Application of DSC in food research and food quality assurance. J Thermal Anal 47: 1787-1803.

24. Hinz HJ, Schwarz FP (2001) Measurement and analysis of results obtained on biological substances with differential scanning calorimetry. The Journal of Chemical Thermodynamics 73: 745-759.

25. Hemminger W, Hohne G (1984) Calorimetry: Fundamentals and Practice, Verlag Chemie, Weinhein, Germany.

26. Pierce MM, Raman CS, Nall BT (1999) Isothermal titration calorimetry of protein-protein interactions. Methods 19: 213-221.

27. Prabhu NV, Sharp KA (2005) Heat capacity in proteins. Annu Rev Phys Chem 56: 521-548.

28. Smith BN, Hansen LD, Breidenbach RW, Criddle RS, Rank DR, et al. (2000) Metabolic heat rate and respiratory substrate changes in aging potato slices. Thermochim Acta 349: 121-124.

29. Gomez Galindo F, Roculli P, Wadso L, Sjoholm I (2005) The potential of isothermal calorimetry in monitoring and predicting quality changes during processing and storage of minimally processes fruits and vegetables. Trends Food Sci Technol 16: 325-331.

30. Wadso L, Gomez Galindo F (2009) Isothermal calorimetry for biologica applications in food science and technology. Food Control 20: 956-961. 